\title{
Smart Maritime Diplomacy: Diplomasi Maritim Indonesia Menuju Poros Maritim Dunia
}

\author{
Najamuddin Khairur Rijal \\ Universitas Muhammadiyah Malang
}

\begin{abstract}
ABSTRAK
Artikel ini mengkaji mengenai upaya diplomasi maritim Indonesia khususnya di Asia Tenggara dan ASEAN untuk mewujudkan visi Poros Maritim Dunia (PMD). PMD adalah jargon unggulan pemerintahan Joko Widodo yang bertujuan untuk mewujudkan cita-cita Indonesia sebagai negara maritim maju, mandiri, kuat serta berkontribusi positif bagi dunia. Melalui pendekatan penelitian deskriptifkualitatif, untuk menjawab bagaimana upaya diplomasi maritim Indonesia, data primer dikumpulkan melalui telaah terhadap laporan kinerja tahunan Kementerian Luar Negeri serta Kementerian Kelautan dan Perikanan. Adapun data sekunder diperoleh melalui penelusuran berbagai literatur yang berkaitan dengan PMD dan diplomasi maritim Indonesia di Asia Tenggara dan ASEAN. Dengan menggunakan konseptualisasi diplomasi maritim Christian Le Miere, artikel ini menunjukkan bahwa upaya diplomasi maritim Indonesia mengintegrasikan antara pendekatan soft melalui kerja sama dan upaya persuasif dengan pendekatan hard melalui tindakan koersif. Oleh penulis, cara tersebut disebut sebagai Smart Maritime Diplomacy.
\end{abstract}

Kata-kata Kunci: diplomasi maritim, ASEAN, Asia Tenggara, poros maritim

This article examines the efforts of Indonesia's maritime diplomacy, especially in Southeast Asia and ASEAN to realize the World Maritime Axis (WMA) vision. WMA is the "jargon" of the Joko Widodo government to realize Indonesia's ideals as an advanced, independent, and strong maritime state, and has positive contribution to the world. Through a descriptive-qualitative research approach, to answer the efforts of Indonesian maritime diplomacy, the primary data was collected through a review of the annual reports of the Ministry of Foreign Affairs and the Ministry of Maritime Affairs and Fisheries. The secondary data is obtained through various literature related to WMA and Indonesian maritime diplomacy in Southeast Asia and ASEAN. By using Christian Le Miere's conceptualization of maritime diplomacy, this article shows that Indonesia's maritime diplomacy efforts integrate the soft approach through cooperation and persuasive efforts with a hard approach through coercive action. By the author, this efforts is referred as Smart Maritime Diplomacy.

Keywords: ASEAN, maritime diplomacy, Southeast Asia, maritime axis 
Artikel ini fokus pada bagaimana pemerintahan Joko Widodo (Jokowi) melakukan upaya diplomasi maritim, khususnya di kawasan Asia Tenggara dan ASEAN, menuju perwujudan visi menjadi Poros Maritim Dunia (PMD). Sebagaimana dipahami, sejak terpilihnya Jokowi sebagai presiden ketujuh Indonesia, diskursus mengenai PMD mengemuka sebagai jargon unggulan pemerintah. Melalui visi PMD, pemerintahan Jokowi-Jusuf Kalla bercita-cita untuk mengembalikan kejayaan maritim Indonesia dan menjadikan Indonesia sebagai negara maritim yang maju, mandiri, kuat sekaligus berkontribusi positif bagi keamanan dan perdamaian dunia, namun dengan tetap berorientasi pada kepentingan nasional.

Argumen utama artikel ini adalah, bahwa diplomasi maritim yang dilakukan oleh Indonesia di kawasan mengintegrasikan dua pendekatan diplomasi maritim. Pertama, upaya diplomasi dalam bentuk soft maritime diplomacy melalui kerja sama dan persuasi. Kedua, upaya diplomasi dalam bentuk hard maritime diplomacy melalui tindakan koersif dalam bentuk kebijakan tegas terhadap pelanggaran illegal fishing. Pengintegrasian dua bentuk diplomasi maritim pada saat yang bersamaan tersebut, oleh penulis, disebut sebagai smart maritime diplomacy. Meminjam istilah smart power yang diperkenalkan oleh Joseph Nye, smart martime diplomacy dimaknai sebagai bentuk integrasi antara kekuatan atau pendekatan soft dan hard Indonesia dalam diplomasi maritim untuk mewujudkan visi PMD.

Untuk menjabarkan argumen tersebut, artikel ini dimulai dengan menggambarkan cita-cita poros maritim dan pemaknaannya. Selanjutnya, mengetengahkan diskusi tentang pentingnya diplomasi maritim bagi Indonesia sekaligus penjelasan tentang konseptualisasi diplomasi maritim. Pada bagian pembahasan berikutnya, penulis menjabarkan tiga bentuk upaya diplomasi maritim Indonesia hingga memberikan penegasan tentang smart maritime diplomacy sebagai pendekatan diplomasi maritim Indonesia dalam usaha perwujudan cita-cita PMD.

\section{Cita-Cita Poros Maritim Dunia}

Gagasan untuk menjadikan Indonesia sebagai PMD dikemukakan oleh JokowiJusuf Kalla dalam kampanyenya pada pemilihan umum tahun 2014. Gagasan itu terangkum melalui paparan visi misi dan program aksi yang disusun setebal 41 halaman dengan judul Jalan Perubahan untuk Indonesia yang Berdaulat, Mandiri, dan Berkepribadian. Visinya adalah "Terwujudnya Indonesia yang berdaulat, mandiri dan berkepribadian berlandaskan gotong royong", yang berusaha diwujudkan melalui sembilan agenda prioritas yang dikenal dengan Nawa Cita (Widodo \& Kalla 2014).

Kemudian dari pada itu, perwujudan visi tersebut melahirkan tujuh misi di mana pada misi ketiga dan keenam berkaitan dengan cita-cita untuk menjadi negara maritim. Misi ketiga adalah "Mewujudkan politik luar negeri bebas-aktif dan memperkuat jati diri sebagai negara maritim.” Adapun misi keenam yakni "Mewujudkan Indonesia sebagai negara maritim yang mandiri, maju, kuat, dan berbasiskan kepentingan nasional" (Jokowi and Kalla 2014). Hal ini setidaknya memberi isyarat bahwa arah orientasi pembangunan yang hendak dilakukan adalah pembangunan berbasis maritim sejalan dengan kondisi alamiah Indonesia sebagai negara kepulauan (archipelagic state).

Selanjutnya, setelah ditetapkan sebagai pasangan Presiden-Wakil Presiden terpilih oleh Komisi Pemilihan Umum (KPU), Jokowi-Jusuf Kalla menyampaikan pidato 
kemenangan. Menariknya, pidato tersebut disampaikan di atas kapal pinisi "Hati Buana Setia”, di Pelabuhan Sunda Kelapa Jakarta pada 22 Juli 2014. Disampaikan di pelabuhan dan di atas kapal, pidato tersebut memberi isyarat untuk mengembalikan semangat Indonesia sebagai negara maritim yang pernah berjaya (Jalesveva Jayamahe). Dalam pidato kemenangannya yang berjudul "Saatnya Bergerak bersama", Jokowi menegaskan pentingnya semangat gotong-royong untuk mewujudkan citacita Indonesia sebagai negara maritim. Kata Jokowi, "Semangat gotong-royong itulah yang akan membuat bangsa Indonesia bukan saja akan sanggup bertahan dalam menghadapi tantangan, tapi juga dapat berkembang menjadi poros maritim dunia, locus dari peradaban besar politik masa depan” (Prasetya 2014).

Setelah resmi dilantik pada 20 Oktober 2014, dalam pidato perdananya sebagai presiden, Jokowi kembali menegaskan visi maritimnya untuk mewujudkan Jalesveva Jayamahe, yakni untuk mengembalikan kejayaan Indonesia di masa lalu sebagai negara maritim. Samudra, laut, selat dan teluk, menurutnya, adalah masa depan peradaban Indonesia. Dalam pidatonya itu, Jokowi mengutip pernyataan Presiden Soekarno dengan menegaskan, "bahwa untuk membangun Indonesia menjadi negara besar, negara kuat, negara makmur, negara damai, kita harus memiliki jiwa cakrawati samudera; jiwa pelaut yang berani mengarungi gelombang dan hempasan ombak yang menggulung" (Setiadji 2014). Pernyataan tersebut semakin menegaskan bahwa kebijakan pemerintahan Jokowi-Jusuf Kalla akan diarahkan pada pengembangan dimensi maritim dengan segala potensinya. Salah satu langkah awal yang dilakukan ditunjukkan dengan pembentukan Kementerian Koordinator Bidang Kemaritiman, lembaga kementerian koordinator yang belum pernah ada sebelumnya, setidaknya sebagai penegasan bahwa aspek maritim menjadi fokus utama pemerintahan.

Adapun pada level internasional, gagasan PMD pertama kali diperkenalkan oleh Jokowi saat menyampaikan pidato di forum Konferensi Tingkat Tinggi Asia Timur (East Asia Summit/EAS) ke-9 pada 13 November 2014 di Naypyidaw, Myanmar. Jokowi menegaskan bahwa PMD ditopang oleh lima pilar utama (Kementerian Luar Negeri RI 2014). Kelima pilar tersebut adalah pembangunan kembali budaya maritim Indonesia melalui pendefinisian kembali identitas nasional sebagai bangsa maritim; menjaga dan mengelola sumber daya laut dengan fokus membangun kedaulatan pangan laut; mendorong pengembangan infrastruktur dan konektivitas maritim; melakukan diplomasi maritim untuk membangun bidang kelautan; dan membangun kekuatan pertahanan maritim.

Melalui penyampaian konsep PMD di fora internasional, menurut Kementerian Luar Negeri dalam laporan kinerjanya, Indonesia telah menegaskan posisinya yang siap membuka kerja sama di bidang maritim dengan berbagai negara untuk mendukung kemajuan perekonomian Indonesia (Kementerian Luar Negeri RI 2015). Kebijakan ini juga disebut terobosan baru dalam sejarah kebijakan luar negeri Indonesia. Sebab, selama ini aspek maritim belum sepenuhnya diposisikan sebagai fokus utama, dan pembangunan nasional selama lebih banyak berorientasi darat.

Konsepsi poros maritim ini, menurut Lembong, menunjukkan adanya upaya pengarusutamaan pembangunan nasional di laut untuk mewujudkan Indonesia sebagai negara maritim (Lembong 2015). Gagasan ini kiranya menjadi seruan untuk kembali ke jati diri Indonesia dan identitas nasional sebagai negara kepulauan yang pernah berjaya di laut sebelum datangnya kolonialisme bangsa-bangsa Eropa memutus kejayaan itu. Karena Portugis, Spanyol, hingga terutama Belanda, menguasai kejayaan 
laut Indonesia dan memudarkan jiwa bahari bangsa Indonesia. Praktis, setelah merdeka, masyarakat maupun pemerintah lebih berorientasi pada pembangunan berbasis darat dengan corak kehidupan pada budaya agraris.

\section{Memaknai Poros Maritim Dunia}

Setelah diperkenalkan Jokowi, istilah PMD kemudian ramai diperbincangkan dari berbagai spektrum sudut pandang keilmuan. Menurut Suropati (2016), gagasan Poros Maritim Dunia secara substantif mengandung dua aspek: poros maritim dan dunia. Pertama, poros maritim, secara tegas menunjukkan tekad pemerintah untuk mengubah paradigma berpikir bangsa dari yang selama ini sangat berorientasi pada pembangunan darat menjadi berorientasi kelautan. Kedua, kata "dunia" dalam istilah Poros Maritim Dunia, menegaskan bahwa perwujudan visi maritim tidak sebatas pada lingkup nasional, melainkan juga pada tataran dunia dan global. Pada titik inilah, gagasan PMD dipandang sebagai langkah awal upaya untuk meredefinisi kepentingan nasional Indonesia.

Akan tetapi, di sisi lain, gagasan PMD melahirkan perdebatan dan tarik ulur definisi. Terlebih karena konsepsi PMD, saat itu belum memiliki landasan legal-formal dan aturan normatif dalam bentuk undang-undang, cetak biru, ataupun masterplan. Karena itu, menurut Suropati dkk., PMD menyisakan perdebatan terkait definisi dan tujuan operasional tentang apa dan bagaimana konsepsi PMD itu (Suropati et al. 2016). Akibatnya, konsep PMD banyak menimbulkan misinterpretasi karena tidak adanya dokumen tertulis dari kebijakan tersebut. Setiap instansi pemerintahan kemudian menerjemahkan PMD dan strategi turunannya sendiri-sendiri (Bayu 2016). Hingga tulisan ini ditulis, kiranya satu-satunya landasan normatif tentang PMD adalah Peraturan Presiden Nomor 16 tahun 2017 tentang Kebijakan Kelautan Indonesia.

Dalam berbagai diskusi dan kajian ilmiah, bahkan mengemuka tiga istilah dalam mendefinisikan PMD, terutama tentang definisi "poros" (Suropati et al. 2016). Kelompok pertama, memaknai kata "poros" sebagai pusat atau sumbu. Berarti, PMD sebagai visi untuk menjadikan Indonesia sebagai pusat dari aktivitas kelautan dunia. Kelompok ini menerjemahkan PMD ke dalam bahasa Inggris sebagai Global Maritime Fulcrum. Kelompok kedua, memaknai kata "poros" sebagai penjajaran, seperti pada tahun 1965, Soekarno membentuk poros politik Beijing-Pyongyang-Hanoi-Jakarta. Melalui PMD, Indonesia hendak membangun penjajaran dengan kekuatan lain sehingga dapat menunjang posisi strategis dan kepentingan nasional Indonesia. Kelompok ini menerjemahkan PMD dalam bahasa Inggris menjadi Global Maritime Axis. Kelompok ketiga memahami kata "poros" sebagai jalur pelayaran maritim. Visi PMD bertujuan untuk menguasai jalur pelayaran maritim yang penting bagi dunia, yang melewati perairan Indonesia. Kelompok ini lebih menerjemahkan PMD dalam bahasa Inggris menjadi Global Maritim Nexus.

Dalam konteks tulisan ini, konsep PMD kemudian dimaknai sebagai sebuah citacita untuk, bukan hanya mengamankan tetapi juga, menguasai seluruh perairan Indonesia, terutama perairan yang memiliki posisi strategis sebagai jalur pelayaran dan perdagangan internasional. Asumsi itu sejalan dengan Peraturan Presiden Nomor 16 tahun 2017 tentang Kebijakan Kelautan Indonesia. Dalam Lampiran Peraturan Presiden tersebut, terdapat tujuh pilar strategi kebijakan maritim Indonesia untuk 
mewujudkan visi poros maritim. Perpres ini setidaknya menjadi satu-satunya rujukan tentang konsepsi kebijakan poros maritim. Adapun ketujuh pilar tersebut adalah: (i) pengelolaan sumber daya kelautan dan pengembangan sumber daya manusia; (ii) pertahanan, keamanan, penegakan hukum, dan keselamatan di laut; (iii) tata kelola dan kelembagaan laut; (iv) ekonomi dan infrastruktur kelautan serta peningkatan kesejahteraan; (v) pengelolaan ruang laut dan pelindungan lingkungan laut; (vi) budaya bahari; dan (vii) diplomasi maritim (Kementerian Koordinator Bidang Kemaritiman RI 2017). Lebih lanjut, salah satu pilar dari visi PMD yang secara khusus berkaitan dengan posisi dan peran Indonesia di level internasional, dan terkait relasi Indonesia dengan negara-negara lain sebagai realisasi karakter politik luar negeri yang bebas-aktif, adalah diplomasi maritim. Pembahasan mengenai diplomasi maritim juga menjadi penting karena menjadi salah satu prioritas dari Rencana Pembangunan Jangka Menengah Nasional (RPJMN) 2015-2019, yakni meneguhkan jati diri Indonesia sebagai negara maritim, dengan memperkuat diplomasi maritim sebagai salah satu arah kebijakan dan strategi.

\section{Urgensi Diplomasi Maritim}

Diplomasi maritim merupakan soko guru politik luar negeri Indonesia. Menurut Madu (2014), melalui diplomasi maritim kebijakan luar negeri perlu diabdikan dan ditujukan untuk mencapai kepentingan nasional sesuai dengan Trisakti. Salah satu tujuan dari pentingnya diplomasi maritim adalah untuk mempercepat penyelesaian masalah perbatasan laut Indonesia dengan 10 negara tetangga: Malaysia, Singapura, Thailand, Filipina, Vietnam, India, Palau, Papua Nugini, Australia, dan Timor Leste. Penyelesaian persoalan perbatasan menjadi sangat penting karena berkaitan dengan upaya menjaga keamanan dan integritas kedaulatan wilayah Indonesia (Kementerian Luar Negeri RI 2015). Hal itu menjadi penegasan Menteri Luar Negeri RI, Retno LP Marsudi bahwa kedaulatan Indonesia atas wilayah maritim harus ditegakkan tanpa dapat ditawar (non-negotiable). Sehingga ke depan, menurut Menlu, diplomasi dan kebijakan luar negeri Indonesia harus menonjolkan identitas dan karakter sebagai negara maritim (Setiadji 2014).

Diplomasi maritimjuga ditujukan untuk menjamin integritas wilayah NKRI, kedaulatan maritim dan keamanan/kesejahteraan pulau-pulau terdepan, dan mengamankan sumber daya alam dan ZEE (Kementerian Perencanaan Pembangunan Nasional 2014). Melalui diplomasi maritim itu pula Indonesia mengedepankan penyelesaian masalahmasalah keamanan maritim dengan jalan bekerja sama. Hal itu tersirat dalam pidato yang disampaikan Joko Widodo di EAS ke-9, bahwa,

"Melalui diplomasi maritim, kami mengajak semua mitra-mitra Indonesia untuk bekerja sama di bidang kelautan ini. Bersama-sama kita harus menghilangkan sumber konflik di laut, seperti pencurian ikan, pelanggaran kedaulatan, sengketa wilayah, perompakan, dan pencemaran laut. Laut harus menyatukan, bukan memisahkan, kita semua" (Setiadji 2014).

Lebih lanjut, diplomasi yang dijadikan sebagai haluan politik luar negeri Indonesia adalah diplomasi kekuatan menengah. Maksud dari diplomasi kekuatan menengah adalah, "menempatkan Indonesia sebagai kekuatan regional dengan keterlibatan global secara selektif, dan memberi prioritas pada permasalahan yang secara langsung berkaitan dengan kepentingan bangsa dan rakyat Indonesia" (Widodo \& Kalla 2014). 
Pernyataan tersebut, menurut Rosyidin (2014), menunjukkan bahwa karakter politik luar negeri Jokowi akan cenderung bersifat inward-looking, dengan frasa "foreign policy begins at home" sebagai platform politik luar negeri. Hal ini berbeda dengan pendahulunya, Susilo Bambang Yudhoyono, yang cenderung lebih outward-looking dengan secara aktif berkiprah di pentas global melalui semboyan millions friends, zero enemy dan politik luar negeri ke segala arah (all direction foreign policy).

Kekuatan ekonomi menengah yang dimaksud di atas selanjutnya diwujudkan dengan memperluas keterlibatan Indonesia di kawasan Indo-Pasifik dengan mengintegrasikan dua samudera, yakni samudera Hindia dan samudera Pasifik, sebagai lingkungan strategis pelaksanaan politik luar negeri Indonesia ke depan. Adapun agenda aksi untuk mewujudkan itu, salah satunya adalah dengan mengonsolidasikan kepemimpinan Indonesia di ASEAN serta memperkuat kerja sama dan menjamin sentralitas ASEAN (Widodo \& Kalla 2014). Hal ini karena Indonesia memandang dirinya sebagai "pemimpin alamiah" di kawasan. Pernyataan dalam visi-misi tersebut juga menunjukkan bahwa sasaran dan arah kebijakan luar negeri Indonesia yang pertama adalah pada kawasan Asia Tenggara dan organisasi regional ASEAN.

Demikian halnya dalam konteks diplomasi maritim, sasaran orientasi dari diplomasi maritim Indonesia adalah kawasan Asia Tenggara dan ASEAN, sebelum mendorong keterlibatan yang lebih luas di pentas global. Hal itu tidak terlepas dari berbagai permasalahan maritim yang dialami Indonesia banyak bersentuhan dengan negaranegara tetangga di Asia tenggara, seperti sengketa batas maritim, klaim kepemilikan wilayah maritim, kasus illegal fishing, perompakan, penyelundupan, batas Zona Ekonomi Eksklusif (ZEE), dan lainnya. Selain itu, penegasan adanya orientasi Indonesia untuk bekerja sama di bidang maritim dengan negara-negara di kawasan, baik secara bilateral maupun multilateral ASEAN, diungkapkan dalam pertemuan Menteri Luar Negeri ASEAN pada 28 Januari 2015 di Kinabalu (Arisandy 2017). Hal itu pernah pula ditegaskan oleh Jokowi pada forum KTT ASEAN ke-25 di Myanmar tahun 2014.

\section{Memahami Diplomasi Maritim}

Secara umum, diplomasi merupakan manajemen dalam hubungan antar negara yang dilakukan oleh suatu negara untuk mencapai kepentingan nasional sebagai pelaksanaan dari politik luar negerinya. Konsep diplomasi kemudian mengalami perluasan, baik dalam hal isu maupun aktor, yang selanjutnya melahirkan berbagai bentuk dan jenis diplomasi, salah satunya adalah diplomasi maritim (maritime diplomacy). Secara sederhana, diplomasi maritim merupakan manajemen hubungan antar negara melalui domain maritim. Menurut Miere, diplomasi maritim tidak hanya berarti penggunaan diplomasi untuk mengelola konflik dan ketegangan antar negara terkait permasalahan maritim melalui penyusunan instrumen hukum internasional. Tetapi diplomasi maritim juga merupakan penggunaan aset atau sumber daya dalam domain maritim untuk mengatur hubungan antar negara (Miere 2014). Jika umumnya diplomasi melibatkan diplomat sebagai representasi negara, diplomasi maritim tidak hanya melibatkan policy maker (aktor negara). Diplomasi maritim dapat melibatkan analis dan akademisi untuk mengkaji mengenai tren dan perkembangan yang terjadi dalam hubungan internasional dan keamanan global (Miere 2014). 
Dalam kaitannya dengan itu, Miere mengategorikan diplomasi maritim ke dalam tiga bentuk, yakni kooperatif, koersif dan persuasif (Miere 2014). Pertama, diplomasi maritim kooperatif meliputi keterlibatan berbagai aktor dalam berbagai aktivitas dengan negara lain. Diplomasi maritim yang kooperatif mensyaratkan kerja sama antar aktor dalam menyelesaikan berbagai masalah yang berkaitan dengan aspek kemaritiman, meliputi pertukaran personel, program pendidikan, pertemuan kolaboratif, dan lainnya yang bertujuan untuk confidence-building. Kedua, diplomasi maritim persuasif berbeda dengan kooperatif dalam hal kolaborasi antar aktor. Tujuan dari diplomasi persuasif adalah untuk meningkatkan pengakuan negara atau pihak lain terhadap kekuatan nasional yang dimiliki oleh suatu negara sekaligus membangun wibawa negara tersebut dalam sistem internasional. Hal ini kemudian dapat mempengaruhi secara persuasif pihak lain terhadap kapabilitas yang dimiliki oleh negara tersebut. Cara yang dapat dilakukan, salah satunya, adalah "showing the flag". Showing the flag maksudnya adalah dengan mengerahkan komponen kekuatan maritim dengan mengibarkan bendera (seperti kapal patroli berbendera negara) sebagai penanda eksistensi negara di wilayah kedaulatan maritimnya.

Ketiga, diplomasi maritime koersif atau disebut juga dengan diplomasi kapal meriam. Dalam hal ini, diplomasi maritim dilakukan dengan penggunaan instrumen kekuatan militer atau maritime forces (seperti angkatan laut dengan perangkat-perangkatnya) untuk mengamankan kepentingan nasional suatu negara di perairan. Negara, melalui personel militernya, kemudian akan melakukan penembakan, penyerangan, penyergapan, dan lainnya terhadap setiap pihak yang dipandang melakukan pelanggaran di teritorial lautnya. Oleh Miere, bentuk ini disebut juga dengan hard maritime diplomacy yang melibatkan penggunaan senjata atau kekuatan militer dalam menghadapi ancaman keamanan maritim. Sementara bentuk cooperative disebut juga soft maritime diplomacy yang menggunakan instrumen nonmiliteristik dan mengedepankan kerja sama. Ketiga bentuk diplomasi maritim tersebut pada pembahasan selanjutnya menjadi kerangka untuk melihat bentuk diplomasi maritim menuju visi PMD yang dilakukan pemerintah Indonesia di Asia Tenggara dan ASEAN.

\section{Diplomasi Maritim Kooperatif}

Diplomasi maritim Indonesia dalam upaya mewujudkan visi sebagai PMD dilakukan melalui upaya kerja sama guna menyelesaikan berbagai permasalahan terkait kemaritiman dengan negara-negara tetangga, seperti masalah batas maritim maupun batas ZEE. Upaya diplomasi maritim yang bersifat kooperatif ini dapat dilihat dari usaha Indonesia mendorong pembentukan berbagai forum kerja sama dan kesepakatan bilateral maupun trilateral dengan negara lain di kawasan. Menurut Kementerian Luar Negeri, "forum kerja sama kemaritiman merupakan lembaga, badan, atau wadah antar negara yang dibentuk untuk mengedepankan kerja sama dalam bidang kemaritiman antara lain bidang keamanan dan keselamatan laut, pengelolaan sumber daya kelautan dan pengelolaan perbatasan" (Kementerian Luar Negeri 2016).

Pada tahun 2015, Indonesia berhasil mendorong terbentuknya dua forum. Pertama, forum RI-Malaysia tentang Technical Meeting on Maritime Delimitation. Hasil dari forum RI-Malaysia ini disepakati perlunya penunjukan utusan khusus untuk mempercepat penyelesaian masalah perbatasan, baik batas maritim maupun batas darat dengan Malaysia, mengingat permasalahan perbatasan antar kedua negara 
cukup kompleks (Kementerian Luar Negeri 2016; Direktorat Jenderal Asia Pasifik dan Afrika 2016). Kedua, forum Indonesia-Vietnam mengenai penetapan batas ZEE. Dalam berbagai pertemuan teknis yang telah digelar, hasilnya menunjukkan adanya indikasi perubahan sikap Vietnam untuk menjadikan penyelesaian penetapan batas ZEE sebagai prioritas dalam kerangka kemitraan strategis Vietnam. Selain itu, Vietnam juga menyetujui untuk menjadikan konvensi hukum laut UNCLOS 1982 sebagai landasan hukum penarikan dan penentuan garis batas ZEE (Direktorat Jenderal Asia Pasifik dan Afrika 2016). Ke depan, hasil perundingan dan kesepakatan dengan Vietnam ini, berarti akan memberikan kejelasan bagi Indonesia terkait batas hak berdaulat untuk pengelolaan sumber daya kelautan, khususnya perikanan.

Lebih lanjut, pemerintah Indonesia juga mendorong berbagai kesepakatan melalui perundingan. Berdasarkan Laporan Kinerja Direktorat Jenderal Asia Pasifik dan Afrika Kemenlu RI, terdapat sebanyak 44 naskah kesepakatan hasil perundingan di bidang diplomasi maritim, politik, keamanan, dan perbatasan yang berhasil dicapai Indonesia sepanjang tahun 2017 (Direktorat Jenderal Asia Pasifik dan Afrika 2018). Salah satunya adalah Indonesia mengusulkan pembukaan jalur konektivitas laut dengan Filipina. Usulan ini disampaikan dalam pertemuan Senior Officials' Meeting (SOM) ke-25 Brunei Darussalam-Indonesia-Malaysia-Philippines East ASEAN Growth Area (BIMP EAGA) dan Ministerial Meeting ke-20 BIMP EAGA, di Puerto Princesa, Palawan, Filipina pada 2016. Hasilnya adalah, Indonesia dan Filipina berhasil menyepakati pembukaan Jalur Konektivitas Laut Bitung-Davao. Kesepakatan itu ditegaskan melalui deklarasi bersama di Manila, pada 28 April 2017. Selain itu, Indonesia juga mendorong untuk mengaktifkan forum trilateral bersama Malaysia dan Filipina sebagai tindak tindak lanjut dari Trilateral Cooperative Arrangement Indonesia-Malaysia-Filipina yang disepakati pada tahun 2016. Realisasi dari kerja sama trilateral itu kemudian adalah dengan terlaksananya patroli bersama, yaitu trilateral maritime patrol di Tarakan, Indonesia; trilateral air patrol di Subang, Malaysia; dan trilateral port visit di Tawi-tawi, Filipina (Direktorat Jenderal Asia Pasifik dan Afrika 2018).

\section{Diplomasi Maritim Persuasif}

Selain upaya kooperatif, diplomasi maritim Indonesia juga diimplementasikan melalui upaya persuasif. Upaya persuasif ini dimaknai sebagai tindakan Indonesia yang berusaha mendorong pengakuan negara lain terhadap kontribusi dan kepemimpinan Indonesia dalam urusan kemaritiman. Salah satunya dilakukan dengan mendorong penguatan kerja sama maritim ASEAN melalui berbagai mekanisme, baik mekanisme internal ASEAN maupun mekanisme eksternal ASEAN yang melibatkan negara lain seperti forum EAS dan ASEAN Regional Forum (ARF). Melalui mekanisme ASEAN yang melibatkan negara lain, misalnya, Indonesia secara aktif mendorong implementasi Declaration on the Conduct of Parties in the South China Sea (DoC) dan diselesaikannya Code of Conduct in The South China Sea (CoC) (Kementerian Luar Negeri 2016). Meskipun Indonesia bukan negara yang terlibat dalam klaim dalam konflik Laut China Selatan (LCS), namun masalah LCS mendapat perhatian Indonesia karena dinamika ketegangan di LCS juga berdampak terhadap kepentingan nasional Indonesia terkait aspek-aspek maritim. Karena itu, Indonesia menegaskan posisinya sebagai negara penengah yang tidak berpihak (honest broker). Kemudian, pada tahun 2015 melalui forum EAS, Indonesia mengusulkan perlunya kerja sama maritim antar 
negara-negara yang tergabung dalam EAS melalui pembangunan ekonomi maritim berkelanjutan; pemajuan perdamaian, stabilitas dan keamanan; mengatasi berbagai tantangan lintas batas; konektivitas maritim; dan kerja sama antar lembaga penelitian (Kementerian Luar Negeri 2016). Gagasan ini mendorong lahirnya EAS Statement on Enhancing Regional Maritime Cooperation. Gagasan Indonesia ini menjadi penting karena EAS melibatkan 10 negara ASEAN dan 8 negara non-ASEAN yang memiliki pengaruh dan kepentingan strategis di kawasan.

Lebih lanjut, dalam berbagai forum seperti EAS maupun ARF, Indonesia juga terus mendorong perlunya tindakan bersama dalam upaya pemberantasan Illegal, Unreported and Unregulated (IUU) Fishing. Secara aktif dan konsisten, Indonesia mendorong agar IUU Fishing dapat dimasukkan sebagai bagian dari kejahatan lintas batas (transnational crimes). Melalui ARF, Indonesia berhasil mendorong lahirnya kesepakatan ARF Statement on Cooperation to Prevent, Deter, and Eliminate IUU Fishing pada Agustus 2017 dalam 24th ARF Minister's Meeting. Dalam forum EAS, Indonesia mendorong pembentukan suatu instrumen ASEAN dalam pemberantasan IUU Fishing dan memasukkannya dalam kategori kejahatan transnasional (Kementerian Luar Negeri 2016). Kemudian, melalui kemitraan ASEAN-Uni Eropa, Indonesia juga mengusulkan agar IUU Fishing diakui secara global sebagai kejahatan transnasional dalam Pertemuan ke-4 ASEAN-EU High Level Dialogue on Maritime Security Cooperation (Kementerian Luar Negeri Republik Indonesia 2018).

Adapun melalui mekanisme internal ASEAN, dalam forum-forum yang dihadiri oleh sepuluh negara anggota, Indonesia mendorong kesepakatan kerja sama di sektor perikanan untuk mencegah masuknya produk perikanan hasil IUU Fishing ke dalam regional supply chain, yang berhasil disepakati dalam the 37th Meeting of the ASEAN Ministers on Agriculture and Forestry (AMAF). Indonesia juga memprakarsai ASEAN Guidelines for Preventing the Entry of Fish and Fishery Products from IUU Fishing Activities into the Supply Chain, yang selanjutnya disahkan dalam oleh Pertemuan Menteri Pertanian ASEAN di Filipina (Kementerian Luar Negeri 2016). Selanjutnya, pada tahun 2017, saat menjadi tuan rumah pertemuan ke-7 ASEAN Maritime Forum (AMF) di Jakarta, Indonesia mendorong beberapa isu penting seperti IUU Fishing, crimes in fisheries, bajak laut, dan perampokan bersenjata di laut agar diangkat dalam agenda AMF (Kementerian Luar Negeri Republik Indonesia 2018). Perhatian dan komitmen Indonesia pada persoalan IUU Fishing juga ditunjukkan dengan inisiatif untuk membentuk Konvensi Regional tentang IUU Fishing.

Upaya mendorong lahirnya konvensi tersebut adalah melalui penyelenggaraan Regional Conference on the Establishment of a Regional Convention against IUU Fishing and Its Related Crimes secara berkala, yang pertama kali digelar di Bali pada tahun 2016. Pada tahun yang sama, Indonesia juga menyelenggarakan simposium internasional Symposium Fisheries Crime (FishCRIME) tentang kejahatan perikanan (Riska 2017).Capaian diplomasi Indonesia di bidang maritim juga ditunjukkan dengan dimasukkannya beberapa poin penting dalam High Level Task Force (HLTF) on ASEAN Community's Post-2015 Vision, seperti perluasan kerja sama maritim ASEAN untuk menanggulangi terorisme, kejahatan lintas negara dan transboundary challenges di wilayah laut, termasuk IUU fishing, penyelundupan, dan trafficking in persons. Pertemuan HLTF ini dipandang memiliki arti strategis karena akan melandasi arah kerja sama ASEAN pada periode 2016-2025 (Direktorat Jenderal Kerja Sama ASEAN 2016). 
Kemudian, Indonesia juga menginisiasi pembentukan ASEAN Seaport Interdiction Task Force (ASITF) pada tahun 2015 yang selanjutnya didukung oleh seluruh negara ASEAN. ASITF menjadi penting bagi Indonesia karena wilayah perairan Indonesia yang luas rawan bagi masuknya bagi berbagai produk ilegal, termasuk narkotika. Tidak hanya itu, dalam pertemuan ke-5 AMF di Vietnam, Indonesia juga mengajukan usulan tentang urgensi pembentukan ASEAN Coast Guard Forum (ACGF). Usulan tersebut selanjutnya ditindaklanjuti dengan pertemuan Experts' Group Meeting (EGM) on the $A C G F$ pada tahun 2015 di Filipina (Kementerian Luar Negeri 2016).

Upaya persuasif dalam diplomasi maritim Indonesia juga dilakukan Indonesia dengan mengambil peran penting dalam kepemimpinan di ASEAN. Upaya tersebut dapat dilihat sebagai usaha pemerintah untuk menunjukkan wibawa, yang selanjutnya dapat menjadi sarana persuasi terhadap negara lain dalam pencapaian kepentingan nasional di bidang maritim. Misalnya, pada tahun 2017, Indonesia mengusulkan dirinya sebagai Chair Marine Protected Area (MPA) Technical Working Group (TWG) sekaligus sebagai Co-Chair Threatened Species TWG periode 2018-2020. Indonesia juga mengajukan diri menjasi tuan rumah MPA Regional Exchange (REX), Q2 di Raja Ampat; Governance Working Group (CMWG dan FRWG) Meeting April 2018; CCA Blue Carbon Training, Q3 di Bali, serta Our Ocean Conference, di Bali. (Direktorat Jenderal Asia Pasifik dan Afrika 2018).

\section{Diplomasi Maritim Koersif}

Selain dua bentuk diplomasi maritim yang dipaparkan di atas, upaya diplomasi maritim Indonesia juga ditunjukkan melalui cara-cara koersif. Cara koersif itu ditunjukkan melalui tindakan tegas penegakan hukum melalui kebijakan membakar dan menenggelamkan kapal-kapal asing yang melakukan aktivitas penangkapan ikan secara ilegal di wilayah perairan Indonesia. Berdasarkan laporan Kementerian Kelautan dan Perikanan (KKP), sepanjang tahun 2015 penindakan hukum yang dilakukan oleh KKP berupa penenggelaman kapal, pemeriksaan, pemulangan anak buah kapal (ABK), dan penangkapan terhadap kapal ilegal. Pemerintah telah menenggelamkan sebanyak 113 kapal ilegal berbagai negara seperti Malaysia, Filipina, Vietnam, Thailand, Papua Nugini, Tiongkok, Panama, dan lainnya; memeriksa 23.041 kapal; memulangkan ABK asing sebanyak 1.020 orang atas kasus perbudakan; serta menangkap 157 unit kapal ilegal sepanjang tahun 2015 (Kementerian Kelautan dan Perikanan 2016).

Kemudian pada tahun 2016, penindakan hukum berupa proses lebih lanjut oleh aparat dilakukan terhadap 136 unit kapal dari 149 unit kapal ikan asing yang melakukan pelanggaran illegal fishing (Kementerian Kelautan dan Perikanan 2017). Hingga Maret 2017, pemerintah melalui Satuan Tugas (Satgas) 511 telah menenggelamkan 317 kapal asing. Satgas 511 sendiri adalah kerja sama multi instansi antara Kementerian Kelautan dan Perikanan, TNI Angkatan Laut, Kepolisian RI, dan Kejaksaan Agung untuk pemberantasan illegal fishing. Satgas ini dibentuk melalui Peraturan Presiden Nomor 115 tahun 2015 (Yakti and Susanto 2017). Selain itu, pemerintah Indonesia juga secara aktif melakukan pengawasan melalui Operasi Kapal Pengawas di Wilayah Pengelolaan Perikanan Negara Republik Indonesia (WWP-NRI) dengan rata-rata hari operasi sebanyak 277 hari layar di wilayah barat dan di wilayah timur sebanyak 257 hari layar. Tujuan pengawasan tersebut adalah dalam rangka mengawasi sumber daya kelautan dan perikanan di seluruh WWP-NRI (Kementerian Kelautan dan Perikanan 
2016). Hasilnya adalah, sepanjang tahun 2016, sebanyak 149 kapal ikan asing dihentikan dan diperiksa serta 140 kapal ditahan oleh kapal pengawas (Kementerian Kelautan dan Perikanan 2017).

\section{Smart Maritime Diplomacy}

Paparan di atas menunjukkan bahwa pemerintah Indonesia mengupayakan diplomasi maritim dengan beragam cara. Hal itu menegaskan bahwa ide besar PMD benar-benar berusaha diwujudkan. Asumsi tersebut setidaknya didasarkan pada kenyataan bahwa untuk pertama kalinya sejak merdeka, Indonesia memiliki Buku Putih Kebijakan Kelautan Indonesia (Ocean Policy) melalui terbitnya Peraturan Presiden Nomor 16 tahun 2017. Kemudian, untuk pertama kalinya Indonesia memiliki Tata Ruang Laut Nasional. Kedua instrumen ini menjadi tonggak sejarah untuk mewujudkan visi PMD sekaligus menunjukkan komitmen pemerintahan Jokowi pada pembangunan yang berorientasi maritim. Kesungguhan itu, menurut Rustam, dapat dilihat dari pembangunan tol laut guna menjamin konektivitas laut, wacana peningkatan armada laut untuk pengamanan di seluruh wilayah maritim Indonesia, dan promosi gagasan PMD secara bilateral, regional, dan multilateral (Rustam 2017).

Adapun cara yang dilakukan Indonesia, sebagaimana temuan penelitian ini, adalah dengan mengintegrasikan tiga bentuk diplomasi maritim sebagaimana yang dikemukakan oleh Miere. Pertama, cara kooperatif yang dilakukan melalui diplomasi untuk mendorong kerja sama secara bilateral dengan Malaysia, Vietnam, dan Filipina serta trilateral antara Indonesia-Malaysia-Filipina. Dengan tujuan untuk menyelesaikan masalah batas maritim dan tumpang tindih ZEE yang diwujudkan melalui melalui pertemuan teknis dan pertemuan kolaboratif dengan Malaysia dan Vietnam; menjalin konektivitas laut melalui deklarasi bersama dengan Filipina; serta menghadapi ancaman keamanan maritim bersama dengan agenda patroli bersama di wilayah perairan Indonesia-Malaysia-Filipina.

Kedua, diplomasi maritim dalam bentuk persuasif dilakukan untuk memperoleh dan meningkatkan pengakuan negara lain terhadap wibawa kedaulatan maritim Indonesia. Upayanya diwujudkan dengan menggagas kerja sama maritim di level regional melalui EAS dan ARF. Selain itu, usulan agar IUU Fishing dimasukkan sebagai kejahatan transnasional, perlunya penyusunan suatu mekanisme atau instrumen hukum guna memberantas IUU Fishing dan kesepakatan tentang IUU Fishing menunjukkan bahwa Indonesia berusaha melakukan persuasi. Muaranya berkaitan erat dengan kepentingan Indonesia sebagai negara kepulauan yang menghadapi berbagai ancaman keamanan maritim. Sekaligus dapat dilihat sebagai upaya Indonesia untuk menegaskan kedaulatan maritimnya, integritas teritorial, identitas nasional, dan wibawa negara dalam sistem internasional. Ketiga, kebijakan koersif melalui penindakan terhadap kapal-kapal asing yang melakukan pelanggaran di wilayah teritorial maritim Indonesia menunjukkan bahwa selain cara-cara yang bersifat lunak, Indonesia juga mampu melakukan tindakan tegas dan keras. Bentuk koersif ini juga menunjukkan bahwa kedaulatan maritim adalah hal esensial bagi Indonesia dan karena itu pemerintah mengerahkan komponen kekuatan maritim sebagai bukti eksistensi negara di wilayah kedaulatan maritimnya.

Tiga bentuk diplomasi maritim yang dilakukan oleh Indonesia menunjukkan bahwa 
pemerintah mengintegrasikan cara-cara soft maritime diplomacy (koorperatif dan persuasif) dan hard maritime diplomacy (koersif). Jika hard maritim diplomacy dilakukan Indonesia sebagai penegasan independensi negara untuk menjaga kedaulatan maritimnya dari segala bentuk ancaman, maka soft maritime diplomacy menuntut Indonesia untuk secara aktif mendorong kerja sama dan kolaborasi sinergis dengan berbagai aktor. Hal ini dapat dipahami mengingat ancaman keamanan maritim yang begitu kompleks tidak bisa dihadapi hanya dengan satu cara dan tidak bisa diatasi sendiri oleh satu negara. Karena itu, tindakan tegas negara dibutuhkan dan pada saat yang sama menuntut perlunya kolaborasi dan kerja sama berbagai aktor (baik antar negara, melalui organisasi regional/internasional, dan rezim internasional).

Dalam konteks ini, Indonesia menyadari bahwa visi PMD hanya dapat berusaha diwujudkan melalui partisipasi dan keterlibatan aktifnya untuk di fora internasional (regional) melalui bekerja sama, tetapi juga dengan tidak kehilangan kepentingan nasionalnya dan dengan tetap menunjukkan wibawa dan integritas nasionalnya. Oleh penulis, kombinasi dua pendekatan ini (soft dan hard maritime diplomacy) disebut sebagai smart maritime diplomacy. Smart maritime diplomacy merupakan cara Indonesia dalam mewujudkan visi PMD melalui kombinasi upaya kerja sama dan persuasi (pendekatan soft) dan cara koersi (pendekatan hard).

Istilah smart maritime diplomacy sendiri diadopsi dari terminologi smart power yang diperkenalkan oleh Joseph Nye. Menurut Nye, "smart power as the combination of the hard power of coercion and payment with the soft power of persuasion and attraction" (Nye 2011). Senada dengan itu, Wilson (2008) mendefinisikan smart power sebagai "the capacity of an actor to combine elementer of hard power and soft power in ways that are mutually reinforcing such that the actor's purposes are advanced effectively and efficiently." Dengan demikian, smart maritime diplomacy merupakan diplomasi maritim yang mengombinasikan elemen atau cara-cara soft dan cara hard untuk menguatkan visi PMD Indonesia secara efektif dan efisien, khususnya di level kawasan Asia Tenggara dan organisasi regional ASEAN.

\section{Simpulan}

Upaya diplomasi maritim yang dilakukan Indonesia untuk mewujudkan visinya menjadi PMD diimplementasikan melalui kerja sama, persuasi, dan koersif. Ketiga cara atau bentuk tersebut mengandung dua dimensi kebijakan, yakni soft dan hard mengingat ancaman keamanan maritim membutuhkan upaya komprehensif. Namun demikian, pendekatan hard juga perlu dilakukan oleh Indonesia secara hati-hati. Sebab, pendekatan hard dapat berpotensi menjadi sandungan dalam mencapai kepentingan yang berusaha dipromosikan melalui upaya-upaya kerja sama dan persuasi (soft). Keaktifan Indonesia menyampaikan gagasan, usulan, rekomendasi, dan lainnya di berbagai forum dan kesempatan di level bilateral, trilateral, maupun multilateral menunjukkan betapa Indonesia berusaha menegaskan kepentingannya terhadap aspek maritim. Namun pada saat yang bersamaan, sikap agresif Indonesia di laut teritorialnya melalui kebijakan membakar dan menenggelamkan kapal asing bisa mengusik hubungan baik Indonesia yang berusaha dibangun dengan negara-negara di kawasan Asia Tenggara.

Selain itu, paparan data yang ditunjukkan terkait upaya diplomasi maritim melalui 
kerja sama, persuasi, dan koersi menunjukkan bahwa domain dari diplomasi maritim bukan hanya angkatan laut (naval maritime diplomacy), tetapi melibatkan berbagai elemen negara dan lembaga pemerintahan. Temuan penelitian ini menunjukkan bahwa diplomasi maritim Indonesia dilakukan dengan mengintegrasikan berbagai cara dan dengan melibatkan berbagai aktor menuju pada satu visi dan cita-cita sebagai poros maritim. Temuan penelitian ini berkontribusi pada pengembangan kajian diplomasi maritim, memperkaya khazanah kajian politik luar negeri Indonesia serta kajian kawasan Asia Tenggara dan ASEAN.

\section{Ucapan Terima Kasih}

Ucapan terima kasih disampaikan kepada Direktorat Penelitian dan Pengabdian Kepada Masyarakat (DPPM) UMM yang telah mendanai penelitian ini melalui skim Penelitian Pengembangan Ipteks (P2I) tahun 2018. Perlu penulis sampaikan pula, bahwa sebagian isi dari tulisan ini pernah dipresentasikan dalam Pertemuan Akademik dan Forum Komunitas "Kebijakan Luar Negeri dan Diplomasi Kontemporer" dalam Konvensi Nasional IX Asosiasi Ilmu Hubungan Internasional Indonesia (AIHII) tahun 2018 di Tanjungpinang.

\section{Referensi}

\section{Buku dan Bab dalam Buku}

Jokowi, and Jusuf Kalla. 2014. Jalan Perubahan Untuk Indonesia Yang Berdaulat, Mandiri, Dan Berkepribadian: Visi Misi Dan Program Aksi. Jakarta: Tim Jokowi-JK.

Lembong, Bernhard. 2015. Poros Maritim. Jakarta: Pustaka Margaretha.

Miere, Christian Le. 2014. Maritime Diplomacy in the 21st Century: Drivers and Challenges. New York: Routledge.

Nye, Joseph S. 2011. The Future of Power. New York: Public Affairs.

Suropati, Untung, Yohanes Sulaiman, and Ian Montratama. 2016. Arungi Samudera Bersama Sang Naga: Sinergi Poros Maritim Dunia Dan Jalur Sutra Maritim Abad Ke-21. Jakarta: Elex Media Komputindo.S

\section{Jurnal dan Jurnal Daring}

Madu, Ludiro. 2014. "Reorientasi Politik Luar Negeri Indonesia Pada Pemerintahan Joko Widodo 2014-2019.” Transnasional: Jurnal Ilmu Hubungan Internasional 9 (2): 104-17.

Riska, Ela. 2017. "Diplomasi Maritim Indonesia Terhadap Aktivitas Penangkapan Ikan Ilegal (Illegal Fishing) Oleh Nelayan China Di ZEEI Perairan Kepulauan Natuna.” Jurnal Prodi Diplomasi Pertahanan 3 (2): 33-47. 
Rustam, Ismah. 2017. "Kebijakan Keamanan Maritim Di Perbatasan Indonesia: Kasus Kejahatan Di Laut Sulawesi-Laut Sulu.” Jurnal Penelitian Politik 14 (2): 161-77.

Wilson, Ernest J. 2008. "Hard Power, Soft Power, Smart Power." The Annals of the American Academy of Political and Social Science 616 (March 2008). doi:10.1177/0002716207312618.

Yakti, Probo Darono, and Joko Susanto. 2017. "Poros Maritim Dunia Sebagai Pendekatan Strategi Maritim Indonesia: Antara Perubahan Atau

Kesinambungan Strategi ?” Global \& Strategis 11 (2): 108-25. doi:10.20473/jgs. v11i2.5355.

\section{Artikel Daring}

Arisandy, Yuni. 2017. “Indonesia Dorong Kerja Sama Maritim Di ASEAN.” Antaranews. com. https://www.antaranews.com/berita/476879/indonesia-dorong-kerjasama-maritim-di-asean.

Bayu, Dimas Jarot. 2016. “Pemerintah Diminta Susun ‘Blueprint' Poros Maritim Dunia.” Kompas.com. http://nasional.kompas.com/read/2016/o8/31/14033501/ pemerintah.diminta.susun.blueprint.poros.maritim.dunia.

Kementerian Luar Negeri RI. 2014. "Presiden Jokowi Deklarasikan Indonesia Sebagai Poros Maritim Dunia.” Siaran Pers Kemlu.go.id. https://www.kemlu.go.id/id/ berita/siaran-pers/Pages/Presiden-Jokowi-Deklarasikan-Indonesia-SebagaiPoros-Maritim-Dunia.aspx.

Prasetya, Eko. 2014. “Ini Pidato Lengkap Jokowi Di Atas Kapal Pinisi.” Merdeka.com. https://www.merdeka.com/politik/ini-pidato-lengkap-jokowi-di-atas-kapalpinisi.html.

Setiadji, Agus. 2014. "Diplomasi Maritim Untuk Kedaulatan Indonesia." Maritimnews. com. $\quad$ http://maritimnews.com/diplomasi-maritim-untuk-kedaulatanindonesia/.

\section{Dokumen Resmi Pemerintah}

Direktorat Jenderal Asia Pasifik dan Afrika. 2016. Laporan Kinerja Direktorat Jenderal Asia Pasifik Dan Afrika 2015. Jakarta.

---. 2018. "Laporan Kinerja 2017.” Jakarta.

Direktorat Jenderal Kerja Sama ASEAN. 2016. Laporan Kinerja Direktorat Jenderal Kerja Sama ASEAN 2015. Jakarta: Direktorat Jenderal Kerja Sama ASEAN Kementerian Luar Negeri.

Kementerian Kelautan dan Perikanan. 2016. "Laporan Kinerja Kementerian Kelautan Dan Perikanan Tahun 2015.” Jakarta.

---. 2017. Laporan Kinerja Kementerian Kelautan Dan Perikanan 2016. Jakarta: 
Kementerian Kelautan dan Perikanan.

Kementerian Koordinator Bidang Kemaritiman RI. 2017. Kebijakan Kelautan Indonesia. Jakarta: Kementerian Koordinator Bidang Kemaritiman Republik Indonesia.

Kementerian Luar Negeri. 2016. Buku II Informasi Kinerja Laporan Kinerja Kementerian Luar Negeri Tahun 2015. Jakarta: Kementerian Luar Negeri.

Kementerian Luar Negeri Republik Indonesia. 2018. Laporan Kinerja Tahun 2017. Jakarta: Kementerian Luar Negeri Republik Indonesia.

---. 2015. Laporan Kinerja Kementerian Luar Negeri Tahun 2014. Jakarta.

Kementerian Perencanaan Pembangunan Nasional. 2014. Rancangan Awal Rencana Pembangunan Jangka Menengah Nasional 2015-2019, Buku I: Agenda Pembangunan Nasional. Jakarta: Kementerian Perencanaan Pembangunan Nasional.

\section{Lain - Lain}

Rosyidin, Mohamad. 2014. "Kembali Ke Masa Depan? Membaca Arah Politik Luar Negeri Jokowi Dan Prospek Indonesia Menjadi Pemain Global”, dalam Prosiding Konvensi Nasional Asosiasi Ilmu Hubungan Internasional Indonesia (AIHII) “Kebijakan Luar Negeri Pemerintahan Jokowi: Agenda Dan Prioritas.” Jakarta: Asosiasi Ilmu Hubungan Internasional Indonesia. 
Smart Maritime Diplomacy:

Diplomasi Maritim Indonesia Menuju Poros Maritim Dunia 